\title{
Analysis of non-methane hydrocarbons in air samples collected aboard the CARIBIC passenger aircraft
}

\author{
A. K. Baker, F. Slemr, and C. A. M. Brenninkmeijer \\ Max-Planck-Institut für Chemie (MPI), Air Chemistry Division, Johannes-Joachim-Becher Weg 27, 55128 Mainz, Germany
}

Received: 19 August 2009 - Published in Atmos. Meas. Tech. Discuss.: 6 October 2009

Revised: 18 January 2010 - Accepted: 2 February 2010 - Published: 26 February 2010

\begin{abstract}
The CARIBIC project (Civil Aircraft for the Regular Investigation of the atmosphere Based on an Instrument Container) is a long-term monitoring program making regular atmospheric measurements from an instrument container installed monthly aboard a passenger aircraft. Typical cruising altitudes of the aircraft allow for the study of the free troposphere and the extra-tropical upper troposphere as well as the lowermost stratosphere. CARIBIC measurements include a number of real time analyses as well as the collection of aerosol and whole air samples. These whole air samples are analyzed post-flight for a suite of trace gases, which includes non-methane hydrocarbons (NMHC).

The NMHC measurement system and its analytical performance are described here. Precision was found to vary slightly by compound, and is less than $2 \%$ for the $\mathrm{C}_{2}-\mathrm{C}_{6}$ alkanes and ethyne, and between $1 \%$ and $6 \%$ for $\mathrm{C}_{7}-\mathrm{C}_{8}$ alkanes and aromatic compounds. Preliminary results from participation in a Global Atmospheric Watch (WMO) VOC audit indicate accuracies within the precision of the system. Limits of detection are 1 pptv for most compounds, and up to 3 pptv for some aromatics. These are sufficiently low to measure mixing ratios typically observed in the upper troposphere and lowermost stratosphere for the longer-lived NMHC, however, in air samples from these regions many of the compounds with shorter lifetimes ( $<5$ days) were frequently below the detection limit. Observed NMHC concentrations span several orders of magnitude, dependent on atmospheric region and air mass history, with concentrations typically decreasing with shorter chemical lifetimes.
\end{abstract}

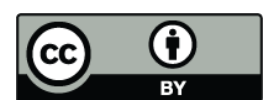

Correspondence to: A. K. Baker (angela.baker@mpic.de)

\section{Introduction}

Beginning in 2005 the CARIBIC project (Civil Aircraft for the Regular Investigation of the atmosphere Based on an Instrument Container; www.caribic-atmospheric.com) has made, and continues to make, monthly deployments of a container-based laboratory equipped to make atmospheric measurements from aboard a Lufthansa Airlines Airbus A340-600 passenger aircraft. Each month four long distance flights are conducted with the 1.5 ton container laboratory installed in the forward cargo bay of the aircraft, followed by de-installation and return to the laboratory. CARIBIC is one of three measurement programs designed to regularly monitor atmospheric composition from aboard passenger aircraft (IGAC, 2007, and references therein). Among these endeavors, CARIBIC is unique in its ability to routinely measure a broad and comprehensive suite of atmospherically significant species. A detailed description of the CARIBIC project and container system can be found in Brenninkmeijer et al. (2007).

The CARIBIC instrument package is fully automated and during each flight carries out a variety of real-time trace gas and aerosol measurements. It also collects aerosol samples and whole-air samples, which are analyzed upon return to the laboratory. Measurements of the whole air samples include those for non-methane hydrocarbons (NMHC), for which the technique is presented here. As of December 2008 over 1000 air samples have been collected and analyzed, with measurements continuing in a near monthly rhythm.

CARIBIC flights originate in Frankfurt, Germany with routes (through December 2008) to India (Chennai), East Asia (Guangzhou and Manila), South America (São Paulo and Santiago de Chile) and North America (Toronto, Houston and Denver). When at cruising altitude (7.2 to $11.9 \mathrm{~km}$; mean altitude $10.7 \mathrm{~km}$ ), the long-distance routes on which

Published by Copernicus Publications on behalf of the European Geosciences Union. 
CARIBIC is deployed typically intersect air masses that are representative of the free troposphere when in the tropics, and both the upper troposphere and lowermost stratosphere (UT/LMS) at mid- to high latitudes. Therefore, CARIBIC allows for the routine monitoring of these atmospheric regions; monitoring of the UT/LMS is of particular interest, as this is a complex, less frequently researched part of the atmosphere.

Non-methane hydrocarbons have a wide range of source distributions and atmospheric residence times, and as such, measurements of these compounds lend themselves to discussion of many atmospheric issues, such as tropospheric ozone formation, the significance of and changes in anthropogenic sources, and timescales associated with transport, mixing and chemistry (Smyth et al., 1996; Parrish et al., 2007); recently, NMHC have also been suggested as a tool for analyzing stratospheric residence times (Ehhalt et al., 2007). CARIBIC NMHC analysis consists of measurement of $\mathrm{C}_{2}-\mathrm{C}_{8}$ alkanes, aromatics (benzene, toluene, ethylbenzene and the xylenes) and ethyne. Here we provide a description of the analytical procedure and system, along with a synopsis of results.

\section{Experimental}

\subsection{Sample collection}

Each month, 28 air samples are collected during CARIBIC flights using an automated air collection system, TRAC (Triggered Retrospective Air Collector); as of December 2008 over 1000 air samples have been collected, 944 of which have been analyzed for NMHC. The air collection system consists of two TRAC sampling units, each of which contains 14 glass sampling flasks of nominally 2.671 (Louwers Hapert, the Netherlands). Glass sampling flasks were preferred to stainless steel to accommodate measurements of other compounds (e.g. alkyl nitrates, $\mathrm{CO}_{2}$ isotopologues). The inlet and outlet connections of each flask are connected by $1 / 10^{\prime \prime}$ stainless steel tubing to two 16-port electrically actuated multi-position switching valves (Valco), with the inlet selector valve being connected to the pumping system and the outlet valve to ambient air via a further solenoid control valve. The multi-position valves at the inlet and outlet positions also serve to seal the flasks. The pumping system consists of two dual-stage metal bellows pumps (Senior Flexonics model PWSC 28823-7) in series to one another; the first pump has the two bellows in parallel while the second has them in series. A pressure sensor (SENSYM) is placed between the outlet of the pumping system and the inlet of the sampler to measure the final pressure in the flasks. A $2 \mu \mathrm{m}$ sintered stainless steel particle filter (Swagelok) is placed at the inlet side of each TRAC to avoid contamination.

Sample collection is fully automated, and is set to begin once the pressure outside the aircraft falls below 480 mbar. The sampling process begins with the flasks being flushed with ambient air for $300 \mathrm{~s}$ (corresponding to about 10 times turnover), after which the outlet side is closed, with the inlet side being closed upon reaching a pressure of 4.5 bar (usually about 10 s after closing the outlet). During the flushing period, pressure is built up, making the actual sampling time a product of the average turnover time (determined in the laboratory for a wide range of external pressures), total filling time, external pressure at the inlet, and final pressure of the flask. Calculated filling times are between 30 and $90 \mathrm{~s}$, with an average of $45 \mathrm{~s}$. Further details on the collection of air samples and the relevant calculations are given in Schuck et al. (2009). The average aircraft speed of about $230 \mathrm{~m} \mathrm{~s}^{-1}$ corresponds to spatial resolution between 7 and $21 \mathrm{~km}(10 \mathrm{~km}$ average $)$ during sample collection. The trigger option has not been implemented and the samples are collected according to a fixed schedule where collection times are distributed evenly along the flight track. Samples are normally analyzed within two weeks of collection for NMHC, and also greenhouse gases (Schuck et al., 2009), at the laboratory in Mainz, and are then circulated between partner laboratories for measurements of halocarbons (Fraser et al., 1999; O'Sullivan, 2007), as well as isotopic composition of $\mathrm{CO}_{2}$ (Assonov et al., 2009). Also the $\mathrm{D} / \mathrm{H}$ ratio of $\mathrm{H}_{2}$ is determined for select flights. To assist with interpretation of the data, measurements made from the flasks are complimented by integrations of the in situ measurements over the sampling time period (e.g. $\mathrm{CO}, \mathrm{O}_{3}, \mathrm{H}_{2} \mathrm{O}$; see Brenninkmeijer et al., 2007). Additionally, for each sample meteorological parameters are calculated based on ECMWF re-analyzed data, and 8-day backward and 2-day forward trajectories are calculated with the KNMI trajectory model, TRAJKS (Scheele et al., 1996; van Velthoven, 2009)

The experiences of other laboratories measuring NMHC from sampling canisters indicate that care should be taken to minimize the time between sample collection and analysis in order to avoid possible artifacts of storage (e.g. trace gas decomposition and growth of compounds) (Apel et al., 2003; Plass-Dülmer et al., 2006). With few exceptions, CARIBIC samples are analyzed for NMHC within two weeks of collection, and for the majority of flights analysis is conducted within one week. Tests where samples have been re-analyzed after between 1 and 3 months have shown the alkanes, aromatics and ethyne to suffer no significant deviation (within the analytical precision of the system) and can therefore be considered stable over the usual turnaround time periods; however, substantial growth in the alkenes is observed, and as such, measurements of these compounds are not taken in to consideration. This result is consistent with findings of NOAA-ESRL, also making NMHC measurements from glass flasks (Pollman et al., 2008). We note that while the processes responsible for alkene formation are not known, growth is observed to some degree in all samples, and is significantly more pronounced in samples collected when realtime analyses indicate low water content, particularly stratospheric samples. 


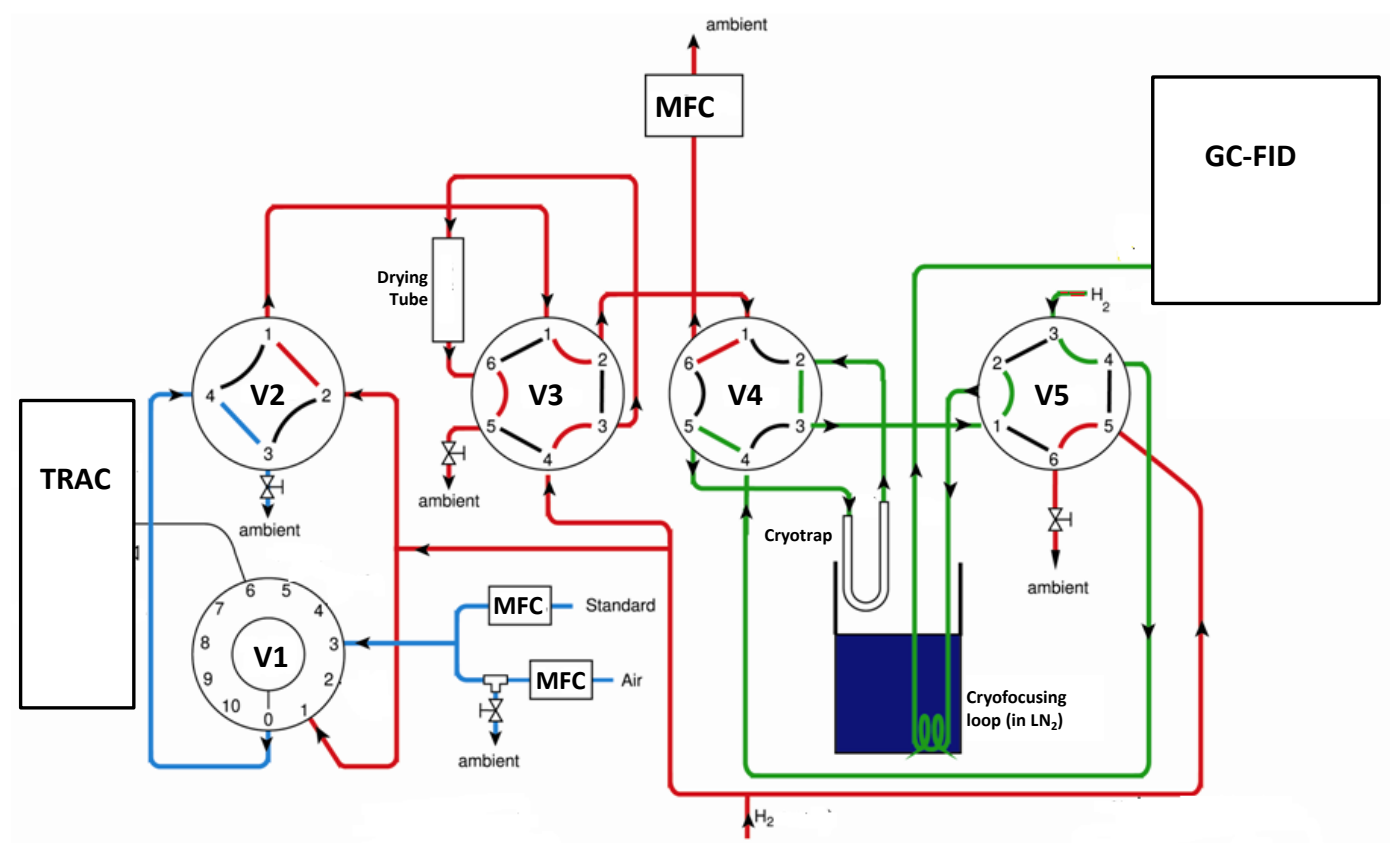

Fig. 1. Schematic of the pre-concentration and GC-FID system for measurement of NMHCs (see text). Lines shown in blue, green and red represent the flow of the analyte being introduced (in this case a standard), the hydrogen carrier and analyte to be delivered to the GC, and hydrogen for pre-concentration and drying agent regeneration, respectively. Bent and straight valve connections represent the two possible valve configurations used during analysis.

\subsection{NMHC analysis}

CARIBIC samples are analyzed for NMHC using an HP6890 gas chromatograph (GC) coupled with a flame ionization detector (FID), where, prior to analysis, the samples are cryogenically pre-concentrated and focused; the analytical process is fully automated and controlled by a microprocessor system. A schematic of the NMHC measurement system, with valves positioned as they are after just before starting a pre-concentration/measurement cycle, is shown in Fig. 1. At this stage the sample to be analyzed has been preconcentrated and is being sent to the cryofocusing loop prior to introduction to the GC, and the drying agent is being regenerated with heating (not shown) and a reverse flow of hydrogen. The TRAC samplers and the system standards are connected to the sampling system via a 10-port automated switching valve (Valco). The two samplers are analyzed sequentially, along with a series of standards, on two consecutive days, subsequent to a calibration analysis of the standards employed. In general, only one NMHC analysis is possible for CARIBIC samples, as the large volume of air required for the measurements ( 11 at STP) means that multiple analyses would severely restrict the amount of sample remaining for other measurements.

At the start of the analysis, the analyte (either an aliquot of standard or air from the TRAC sampler) is introduced to the system and water vapor is removed by passing through a drying tube containing magnesium perchlorate as a drying agent

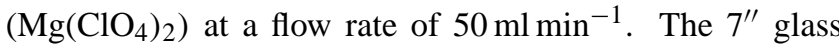
drying tube $\left(1 / 4^{\prime \prime}\right.$ internal diameter) is filled over $4^{\prime \prime}$ with the drying agent, which is confined at each end by glass wool. The drying tube is at $55^{\circ} \mathrm{C}$ while sample is flowing through and is regenerated by heating at $80^{\circ} \mathrm{C}$ for $25 \mathrm{~min}$ while flushing with hydrogen. Heating of the drying agent serves not only as a regeneration step, but has also been shown to significantly reduce any loss of larger $(\mathrm{C} \geq 8)$ NMHC (Rudolph et al., 1986).

Samples collected at typical CARIBIC flight altitudes have low water contents (Schuck et al., 2009). However, as water can negatively influence behavior of the analyte during pre-concentration and on the column, drying is performed to avoid any effects and to ensure uniform water content for all samples. To ascertain that there is no significant influence of the drying agent on NMHC concentrations (i.e. through loss or the introduction of contaminants) 28 samples from two TRACS along with a series of standards, both with and without using the drying tube, while all other parameters were kept unchanged. For the primary standard, which is effectively dry to begin with, agreement between measurements for all compounds was very good, with differences of less than $5 \%$ for all and less than $2 \%$ for $\mathrm{C}_{2}-\mathrm{C}_{7}$ NMHC. Overall agreement between the dried and undried TRAC analyses was good for the $\mathrm{C}_{2}-\mathrm{C}_{4}$ hydrocarbons, with average differences between the measurements of less than $2 \%$. However, for measurements where the drying agent was bypassed during analysis, NMHC with more than 5 carbons were 
sometimes co-eluted with an unidentified compound, most likely an oxygenated volatile organic compound (OVOC); this was also the case for i-butane in two samples. These larger NMHC are also frequently below the limit of detection for the system, making the influence of drying difficult to determine, however, for a sufficient number of undried samples, peak areas could be reliably determined for i-pentane, n-pentane, hexane, benzene and toluene. These had differences of up to $5 \%$ between dried and undried samples. Owing to the frequency of measurements below the limit of detection combined with the influence of co-eluting compounds, peak areas could not be reliably determined for the remaining $\mathrm{C}_{5}-\mathrm{C}_{8} \mathrm{NMHC}$ in those samples where the drying agent was bypassed.

The low levels of NMHC in the atmosphere necessitate pre-concentration of the sample prior to analysis. Therefore, after drying the sample is pre-concentrated by passing through a stainless steel loop $\left(1 / 8^{\prime \prime}, 15 \mathrm{~cm}\right.$ long) filled with Carbopack BHT adsorbent (mesh 60/80). For preconcentration the loop is lowered into in a Dewar where it is held over, but not immersed in, liquid nitrogen and cooled to about $-130^{\circ} \mathrm{C}$. This is sufficiently cold for the quantitative trapping of NMHC while providing for the near complete removal of major atmospheric constituents, such as nitrogen and oxygen, as well as minor constituents, such as methane and carbon dioxide. The sample flow through the system of $50 \mathrm{ml} \mathrm{min}^{-1}$ is controlled by a mass flow controller (MKS Instruments, $100 \mathrm{sccm} \mathrm{N_{2 }}$ ). Using a trapping time of $20 \mathrm{~min}$, a 11 aliquot of sample air (STP) is processed. The loop is isolated from the sample flow after the pre-concentration step, and, following a brief equilibrium period ( $30 \mathrm{~s})$, the sample is desorbed and re-volatilized by lifting the loop from above the liquid nitrogen and heating to $90^{\circ} \mathrm{C}$. The re-volatilized sample is then sent to the cryo-focusing loop, which is a $175 \mathrm{~cm}$ section of ultimetal WCOT CP7120 column (Varian Chrompack, $0.53 \mathrm{~mm}$ ID, $0.8 \mathrm{~mm}$ OD, $1.0 \mu \mathrm{m}$ film thickness) in a flow of $\mathrm{H}_{2}$ carrier gas. A coiled $30 \mathrm{~cm}$ section of the cryo-focusing loop is immersed in liquid nitrogen, thereby trapping the sample. The loop is then lifted from the liquid nitrogen and allowed to heat up to room temperature, thus permitting the analyte to flow into the GC system. Cryofocusing ensures an optimal peak shape, and also serves to more effectively separate the $\mathrm{C}_{2}$, and to a lesser extent the $\mathrm{C}_{3}$ and $\mathrm{C}_{4}$, hydrocarbons before reaching the GC column. Total sample preparation time is $60 \mathrm{~min}$.

The HP6890 GC houses a $150 \mathrm{~m}$ Petrocol DH column ( $0.25 \mathrm{~mm}$ ID, $1.0 \mu \mathrm{m}$ film thickness) connected to an FID, and the analysis is $60 \mathrm{~min}$ long (making the total measurement time with pre-concentration two hours for each sample). The oven operates on a temperature program beginning at $-10{ }^{\circ} \mathrm{C}$, with a final temperature of $200^{\circ} \mathrm{C}$; full parameters are provided in Table 1. Nitrogen and synthetic air used for the system are supplied by cylinders $(99.999 \%$ and $99.9 \%$ purity, respectively) and hydrogen is supplied by a Parker Balston Hydrogen Generator, model H2-300 (99.99999+\%
Table 1. Parameters for the GC program.

\begin{tabular}{ll}
\hline Parameter & Value \\
\hline initial temp & $-10^{\circ} \mathrm{C}$ \\
initial time & $5 \mathrm{~min}$ \\
rate 1 & $8^{\circ} \mathrm{C} \mathrm{min}-1$ \\
final temp & $200^{\circ} \mathrm{C}$ \\
final time & $31.25 \mathrm{~min}$ \\
hold time & $5 \mathrm{~min}$ \\
rate 2 & $-10^{\circ} \mathrm{C} \min ^{-1}$ \\
final temp & $-10^{\circ} \mathrm{C}$ \\
final time & $57.25 \mathrm{~min}$ \\
\hline
\end{tabular}

purity). Prior to introduction to the system the synthetic air is passed over a Pt catalyst heated to $380^{\circ} \mathrm{C}$ to oxidize any contaminant hydrocarbons and then flows through a Supelcarb HC trap. For each analysis, multiple blanks of the synthetic air are analyzed to detect if there are any remaining contaminants. The signal from the FID is output to a PC running Agilent Chemstation software. Each chromatogram is manually reprocessed to ensure correct peak identification, shape and consistent baseline determination. Chromatograms representative of the primary standard and a CARIBIC sample are shown in Fig. 2.

\subsection{Standards and calibration}

Multiple standards are employed during each analysis and include one primary standard and four whole air working standards (Table 2). The primary standard currently in use (NPL07) is a gravimetrically prepared mixture of 30 NMHC in nitrogen purchased from and calibrated by the National Physical Laboratory (Teddington, United Kingdom, NPL Primary Reference Gas Mixture), with a quoted uncertainty of $0.08 \mathrm{ppbv}$ for each compound ( 2\%) (NPL, 2008). Prior to 2007 a different NPL standard was used (NPL04) and this is a standard of similar preparation method, although with slightly different NMHC concentrations, as the NPL07 standard. Comparison between the two shows good agreement (Table 2), and the two standards are occasionally compared to check for drift or instability.

As mixing ratios of the NPL07 primary standard ( $\sim 4$ ppbv) are substantially higher than those observed during CARIBIC flights, the standard is diluted at ratios between 1:100 and 1:20 (giving 40-200 pptv) with synthetic air. The dilution system consists of two mass flow controllers which regulate the amount of standard and synthetic air being introduced to a mixing tube, which is then connected to the system via the 10-port inlet valve. The actual dilution ratio is determined from the relative flows of the primary standard and synthetic air, and the dilutions given above represent the limits of the dilution system. Additionally, these multiple dilutions are used to ensure linearity of the response and proper 

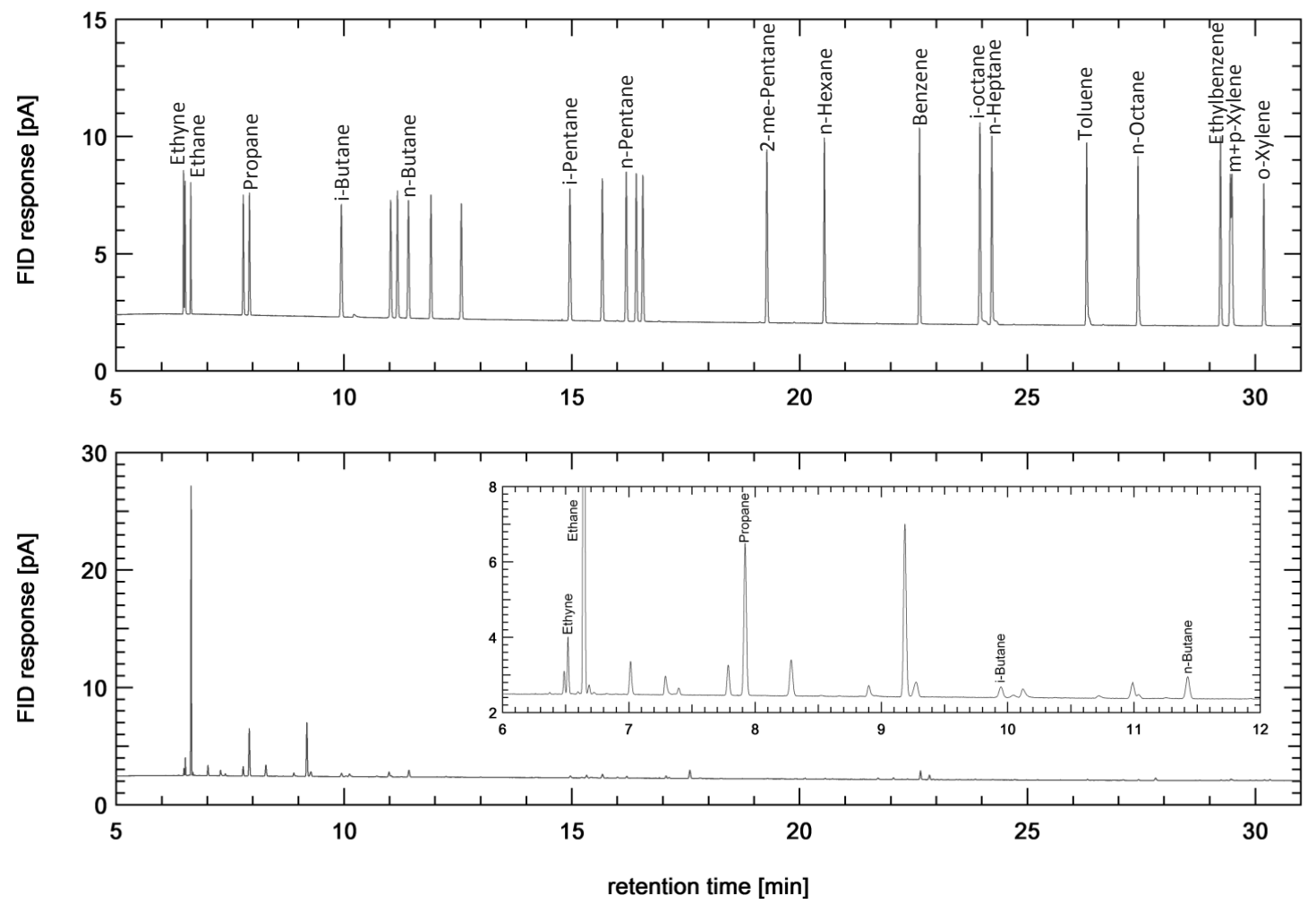

Fig. 2. Chromatograms from analysis of the primary standard (top) and of a sample collected in the upper troposphere (bottom). Peaks analyzed for CARIBIC samples are labeled in the primary standard chromatogram; peaks not considered (e.g. alkenes, halocarbons) are unlabeled.

function of the dilution system. Overall linearity of the system was checked using multiple analyses at these dilutions as well as of the undiluted standard. For all compounds considered the correlation coefficient was better than 0.995 , with offsets being less than 1 pptv.

The primary standard is used to determine per carbon response factors (PCRFs) for individual compounds, and these are in turn used to determine mixing ratios of the CARIBIC samples. For compounds with six or fewer carbons, the PCRFs are nearly identical, and are also stable over long periods of time (Fig. 3). However, compounds with higher carbon numbers (i.e. compounds having longer retention times on the analytical column), give rapidly decreasing responses, while ethyne has a slightly larger response. This behavior has been observed by other laboratories measuring NMHC employing similar techniques (i.e. pre-concentration followed by GC-FID analysis) and is considered to be a product of detector and system parameters and configuration (Colman et al., 2001; Apel et al., 2003). Sample mixing ratios are determined from the individual compound response factors, with the exceptions being 3-methylpentane and cyclohexane, which are not in the primary standard. The carbon response factors for 2-methlypentane and hexane, respectively, are used to determine per carbon response factors for 3-methylpentane and cyclohexane.
In addition to the primary standard, four whole air working standards are employed during the analysis. The SIL191, SIL192 and SIL193 standards were collected in 2005 at the Schauinsland Observatory in Southern Germany, while the CFL1 standard was collected in 2006 atop a building at the institute in Mainz. All working standards were collected in 51 aluminum cylinders (Scott Marin) using a compressor and were dried with Drierite. The main function of these standards is to ensure the stable behavior in the system of samples containing the bulk gases and to check for changes or drift relative to the primary standard. As constraints due to available sample volume make duplicate analyses of the CARIBIC samples impractical, replicate analysis of the working standards were used to evaluate the overall precision of the system for whole air analysis (Table 2). The working standards are calibrated against the NPL standard monthly, immediately prior to analysis of the TRAC samples, and no drift within the system precision has been observed in the NMHC mixing ratios or these standards' relationship to the primary standard. Limits of detection for the system were determined using a combination of working standard and TRAC sample analyses, and represent the larger of three times signal-to-noise or the mixing ratio calculated for the smallest peak that can be reliably integrated. 
Table 2. Standards, limits of detection (LOD), and precision of the GC-FID system.

\begin{tabular}{|c|c|c|c|c|c|c|c|c|c|}
\hline & LOD & NPL07 ${ }^{\mathrm{a}}$ & NPLO4 $^{\mathrm{a}}$ & $\Delta x(\%)^{\mathrm{b}}$ & $\mathrm{CFL}^{\mathrm{c}}$ & SIL191 ${ }^{\mathrm{c}}$ & SIL192 ${ }^{c}$ & SIL193 ${ }^{c}$ & Precision $^{\mathrm{d}}$ \\
\hline Ethyne & 1 & $4.13 \pm 0.08$ & $9.06 \pm 0.18$ & $-1.8 \%$ & $634 \pm 12$ & $143 \pm 1.2$ & $83 \pm 1.2$ & $207 \pm 3.8$ & $0.9 \%$ \\
\hline Ethane & 1 & $4.08 \pm 0.08$ & $8.17 \pm 0.16$ & $-1.6 \%$ & $2455 \pm 17$ & $1099 \pm 7.2$ & $565 \pm 4.2$ & $793 \pm 5.3$ & $0.2 \%$ \\
\hline Propane & 1 & $4.08 \pm 0.08$ & $3.63 \pm 0.07$ & $-2.8 \%$ & $1104 \pm 28$ & $340 \pm 3.8$ & $141 \pm 2.0$ & $261 \pm 3.2$ & $0.8 \%$ \\
\hline i-Butane & 1 & $4.10 \pm 0.08$ & $1.2 \pm 0.04$ & $-2.5 \%$ & $361 \pm 2.8$ & $154 \pm 1.3$ & $123 \pm 1.1$ & $152 \pm 1.3$ & $0.1 \%$ \\
\hline n-Butane & 1 & $3.98 \pm 0.08$ & $1.9 \pm 0.04$ & $-2.4 \%$ & $634 \pm 5.7$ & $189 \pm 1.6$ & $79 \pm 0.8$ & $115 \pm 1.1$ & $0.3 \%$ \\
\hline i-Pentane & 1 & $3.97 \pm 0.08$ & $1.39 \pm 0.03$ & $-2.9 \%$ & $363 \pm 3.5$ & $161 \pm 1.5$ & $122 \pm 1.1$ & $191 \pm 1.5$ & $0.3 \%$ \\
\hline n-Pentane & 1 & $4.03 \pm 0.08$ & $1.11 \pm 0.02$ & $-1.8 \%$ & $253 \pm 2.7$ & $74 \pm 0.8$ & $41 \pm 0.5$ & $58 \pm 0.4$ & $0.4 \%$ \\
\hline 2-methyl-Pentane & 1 & $3.98 \pm 0.08$ & $1.79 \pm 0.04$ & $-2.2 \%$ & $91 \pm 0.8$ & $41 \pm 0.4$ & $33 \pm 0.2$ & $44 \pm 0.3$ & $0.3 \%$ \\
\hline 3-methyl-Pentane & 1 & & $2.77 \pm 0.06$ & & $53 \pm 0.4$ & $22 \pm 0.3$ & $17 \pm 0.2$ & $23 \pm 0.3$ & $0.4 \%$ \\
\hline n-Hexane & 1 & $3.98 \pm 0.08$ & $3.15 \pm 0.06$ & $-1.6 \%$ & $79 \pm 0.6$ & $30 \pm 0.7$ & $19 \pm 0.4$ & $21 \pm 1.1$ & $1.5 \%$ \\
\hline Benzene & 3 & $4.01 \pm 0.08$ & $5.39 \pm 0.11$ & $-2.8 \%$ & $233 \pm 2.5$ & $91 \pm 6.3$ & $40 \pm 2.7$ & $85 \pm 3.2$ & $2.3 \%$ \\
\hline Cyclohexane & 1 & & $4.76 \pm 0.1$ & & $45 \pm 0.5$ & $92 \pm 0.9$ & & $8 \pm 0.2$ & $0.6 \%$ \\
\hline i-Octane & 1 & $4.01 \pm 0.08$ & & & $33 \pm 0.7$ & $20 \pm 1.1$ & $12 \pm 0.4$ & $17 \pm 0.6$ & $3.1 \%$ \\
\hline n-Heptane & 1 & $3.93 \pm 0.08$ & $2.42 \pm 0.05$ & $-1.7 \%$ & $34 \pm 1.6$ & $20 \pm 2.4$ & $14 \pm 1.0$ & & $4.3 \%$ \\
\hline Toluene & 1 & $3.97 \pm 0.08$ & $4.16 \pm 0.08$ & $-3.4 \%$ & $379 \pm 9.7$ & $179 \pm 6.9$ & $149 \pm 5.0$ & $160 \pm 3.2$ & $1.6 \%$ \\
\hline n-Octane & 1 & $3.97 \pm 0.08$ & & & $15 \pm 1.4$ & $14 \pm 1.5$ & $13 \pm 1.3$ & $10 \pm 0.8$ & $4.2 \%$ \\
\hline Ethylbenzene & 3 & $4.1 \pm 0.08$ & $1.7 \pm 0.03$ & $-2.9 \%$ & $56 \pm 4.1$ & $21 \pm 1.9$ & $29 \pm 2.6$ & $16 \pm 1.5$ & $4.1 \%$ \\
\hline $\mathrm{m}+\mathrm{p}-$ Xylene & 3 & $4.06 \pm 0.08$ & $2.11 \pm 0.04$ & $2.8 \%$ & $140 \pm 14$ & $24 \pm 2.4$ & $54 \pm 6.1$ & $23 \pm 1.8$ & $4.6 \%$ \\
\hline o-Xylene & 3 & $4.03 \pm 0.08$ & $1.39 \pm 0.03$ & $-3.6 \%$ & $35 \pm 3.6$ & $11 \pm 1.1$ & $23 \pm 2.6$ & $11 \pm 0.9$ & $5.4 \%$ \\
\hline
\end{tabular}

a values (in ppbv) given by NPL; error represents $95 \%$ confidence level

$\mathrm{b}$ difference between the quoted value of NPL04 and that determined when measured against NPL07 as a percentage of the quoted value.

$\mathrm{c}$ values given in pptv; error represents standard deviation $(1 \sigma)$

$\mathrm{d}$ mean percent relative standard deviation of whole air standard calibrations $(n=5)$

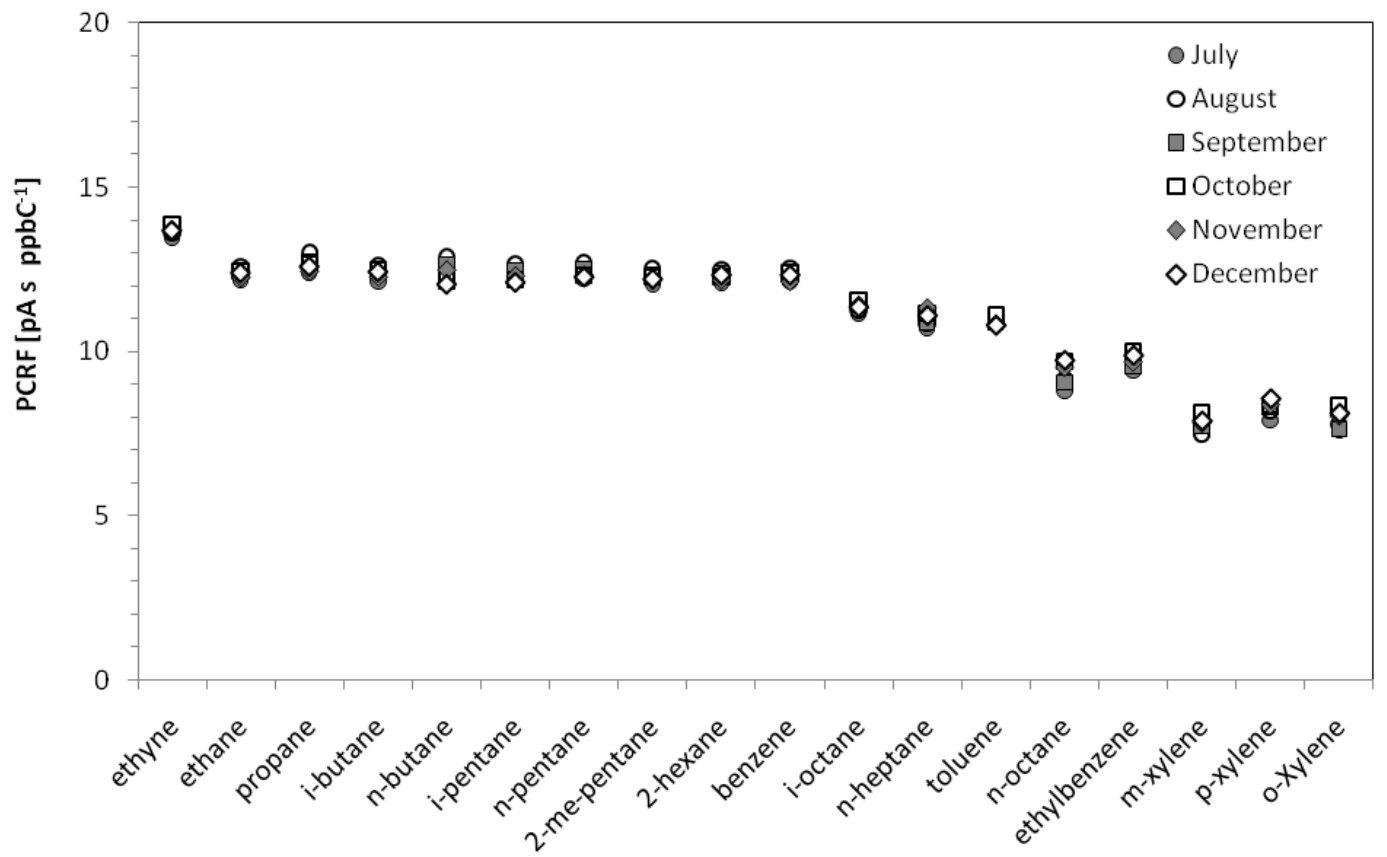

Fig. 3. Six month (July-December 2008) time series of per carbon response factors (PCRFs) determined from the average of the monthly analyses of the NPL standard. Standard deviations are omitted for clarity, but in each month were lower than $1 \%$ for C $\leq 6$, and between 1 and $5 \%$ for higher carbon numbers. Compounds are listed in order of increasing retention time. 
Table 3. Results of comparison with CARIBIC-1 and GAW standards (see text).

\begin{tabular}{|c|c|c|c|c|c|c|c|c|}
\hline & \multicolumn{3}{|c|}{ NPL99 ${ }^{a}$} & \multicolumn{3}{|c|}{$\mathrm{NPLO}^{\mathrm{a}}$} & \multicolumn{2}{|c|}{ GAW } \\
\hline & Concentration & $\% \mathrm{RSD}^{\mathrm{b}}$ & $\Delta x^{\mathrm{c}}(\%)$ & Concentration & $\% \mathrm{RSD}^{\mathrm{b}}$ & $\Delta x^{\mathrm{c}}(\%)$ & $\% \mathrm{RSD}^{\mathrm{b}}$ & $\Delta x^{\mathrm{c}}(\%)$ \\
\hline Ethyne & $9.85 \pm 2.0 \%$ & $0.1 \%$ & $0.8 \%$ & $8.73 \pm 1.9 \%$ & $0.3 \%$ & $-5.7 \%$ & $0.7 \%$ & $-1.5 \%$ \\
\hline Ethane & $7.55 \pm 2.0 \%$ & $0.2 \%$ & $0.9 \%$ & $7.87 \pm 2.0 \%$ & $0.1 \%$ & $0.4 \%$ & $0.2 \%$ & $-0.8 \%$ \\
\hline Propane & $2.86 \pm 1.7 \%$ & $0.2 \%$ & $-1.4 \%$ & $3.50 \pm 2.0 \%$ & $0.2 \%$ & $-1.4 \%$ & $0.6 \%$ & $-0.2 \%$ \\
\hline i-Butane & $3.34 \pm 1.5 \%$ & $0.3 \%$ & $-0.6 \%$ & $1.16 \pm 2.2 \%$ & $0.4 \%$ & $-0.4 \%$ & $0.2 \%$ & $-0.6 \%$ \\
\hline n-Butane & $2.88 \pm 1.7 \%$ & $0.1 \%$ & $0.1 \%$ & $1.83 \pm 1.7 \%$ & $0.4 \%$ & $-1.6 \%$ & $0.1 \%$ & $-0.7 \%$ \\
\hline i-Pentane & $1.32 \pm 1.5 \%$ & $0.1 \%$ & $-0.8 \%$ & $1.34 \pm 2.2 \%$ & $0.3 \%$ & $-0.8 \%$ & $0.3 \%$ & $-0.4 \%$ \\
\hline n-Pentane & $2.94 \pm 1.7 \%$ & $0.2 \%$ & $-2.3 \%$ & $1.07 \pm 1.9 \%$ & $0.3 \%$ & $-0.9 \%$ & $0.4 \%$ & $-0.5 \%$ \\
\hline 2-methyl-Pentane & $3.54 \pm 1.4 \%$ & $0.1 \%$ & $0.7 \%$ & $1.72 \pm 1.7 \%$ & $0.2 \%$ & $0.8 \%$ & & \\
\hline 3-methyl-Pentane & $4.05 \pm 1.4 \%$ & $0.1 \%$ & $1.4 \%$ & $2.67 \pm 1.9 \%$ & $0.2 \%$ & $1.2 \%$ & & \\
\hline n-Hexane & $1.97 \pm 2.0 \%$ & $0.2 \%$ & $0.2 \%$ & $3.03 \pm 2.0 \%$ & $0.5 \%$ & $-0.1 \%$ & & \\
\hline Benzene & $3.81 \pm 1.3 \%$ & $0.1 \%$ & $-0.5 \%$ & $5.19 \pm 1.9 \%$ & $0.6 \%$ & $-0.7 \%$ & $0.4 \%$ & $-0.7 \%$ \\
\hline $\begin{array}{l}\text { Cyclohexane } \\
\text { i-Octane }\end{array}$ & $3.71 \pm 1.4 \%$ & $0.1 \%$ & $1.4 \%$ & $4.58 \pm 2.0 \%$ & $0.4 \%$ & $1.8 \%$ & & \\
\hline n-Heptane & $3.08 \pm 1.6 \%$ & $3.6 \%$ & $-1.2 \%$ & $2.33 \pm 2.1 \%$ & $2.1 \%$ & $-0.9 \%$ & & \\
\hline $\begin{array}{l}\text { Toluene } \\
\text { n-Octane }\end{array}$ & $3.58 \pm 1.4 \%$ & $0.7 \%$ & $-1.4 \%$ & $4.01 \pm 2.0 \%$ & $1.9 \%$ & $-1.5 \%$ & $1.0 \%$ & $-0.8 \%$ \\
\hline $\begin{array}{l}\text { Ethylbenzene } \\
\mathrm{m}+\mathrm{p}-\mathrm{Xylene}\end{array}$ & $1.97 \pm 2.0 \%$ & $1.6 \%$ & $0.9 \%$ & $1.64 \pm 1.8 \%$ & $1.3 \%$ & $-0.9 \%$ & & \\
\hline o-Xylene & $1.11 \pm 1.6 \%$ & $2.5 \%$ & $1.6 \%$ & $1.34 \pm 1.9 \%$ & $4.8 \%$ & $-1.1 \%$ & & \\
\hline
\end{tabular}

a concentrations given in ppbv; error represents the $95 \%$ confidence limit (as a percentage of the concentration)

b $\%$ RSD $=$ percent relative standard deviation $(n=5)$

${ }^{\mathrm{c}}$ difference between the measured and actual/quoted values, as a percentage of the actual concentration

Currently, the CARIBIC project is in its second phase of operation; the first phase began in 1996 and continued through 2002, with measurements conducted from a different, but similarly equipped, instrument container installed onboard an LTU Airlines Boeing 767 passenger aircraft (Brenninkmeijer et al., 1999). During the first phase (CARIBIC-1) NMHC were analyzed using GC-MS (gas chromatography - mass spectrometry) of air samples collected in stainless steel sampling flasks (Mühle et al., 2002; Rhee et al., 2005). To ensure that the calibration scales of the two data sets are in agreement, the NPL standards used during CARIBIC-1 analysis were measured against the current CARIBIC NPL standard using the current GC system. For the majority of NMHC, measured concentrations were within the range of the quoted uncertainties given for the standards, which were between 1.3 and $2.2 \%$ (Table 3). The only two exceptions were n-pentane in NPL99 and ethyne in NPL02, although even their deviations were less than 5\%. It should be noted that the ages of the standards were seven (NPL02) and ten (NPL99) years, which exceeds the guarantee period of two years set by NPL, and the influence of age on standard stability could be a factor influencing comparison. However, overall agreement was good, and no appreciable long-term changes in stability were readily apparent from the measurements, ultimately indicating that measurements from the two phases of CARIBIC are using closely related, traceable scales.
The CARIBIC NPL standard was also compared with that of an outside institution (Institute of Meteorology and Climate Research Forschungszentrum Karlsruhe, IMK-FKU) as part of a multi-institution inter-comparison (official audit) conducted for the World Meteorological OrganizationGlobal Atmospheric Watch (WMO-GAW) program for volatile organic carbon (VOC) analysis. The audit consisted of a round-robin style inter-comparison of several standards. As the rotation between laboratories was not complete at the time of submission, the concentrations of the standards and official, overall results of the audit are not available for publication, and only relative results of one standard can be given here (Table 3). As with the internal comparison between various CARIBIC NPL standards, agreement with the audit standard was very good. Agreement is, as can be determined from Table 3, well within the WMO-GAW guidelines for VOC measurements which recommend precisions of 5\% for $\mathrm{C}_{2}-\mathrm{C}_{5}$ alkanes and/or \pm 15 pptv for mole fractions less than 100 pptv (WMO-GAW, 2007).

\subsection{Sample data}

As CARIBIC samples represent a number of different atmospheric regions and air masses the differences in concentrations between compounds, and also for any single compound in different air samples, can be 2 or 3 orders of magnitude (Table 4). Unsurprisingly, the highest mixing ratios are 
Table 4. Overview of NMHC results for both the upper troposphere and lowermost stratosphere. Mixing ratios are given in pptv.

\begin{tabular}{|c|c|c|c|c|c|c|c|c|}
\hline & \multicolumn{4}{|c|}{ Upper Troposphere $(n=640)$} & \multicolumn{4}{|c|}{ Lowermost Stratosphere $(n=304)$} \\
\hline & Mean $( \pm 1 \sigma)$ & Min & $\operatorname{Max}$ & $\% \mathrm{BDL}^{\mathrm{a}}$ & Mean $( \pm 1 \sigma)$ & Min & $\operatorname{Max}$ & $\% \mathrm{BDL}^{\mathrm{a}}$ \\
\hline Ethyne & $90 \pm 43$ & 18 & 220 & 0 & $31 \pm 22$ & LOD & 117 & 5 \\
\hline Ethane & $575 \pm 217$ & 202 & 1717 & 0 & $352 \pm 164$ & 88 & 1067 & 0 \\
\hline Propane & $72 \pm 58$ & 8 & 385 & 0 & $35 \pm 31$ & LOD & 234 & 4 \\
\hline i-Butane & $9 \pm 10$ & LOD & 65 & 7 & $3 \pm 3$ & LOD & 13 & 51 \\
\hline n-Butane & $14 \pm 17$ & LOD & 113 & 3 & $6 \pm 4$ & LOD & 33 & 15 \\
\hline i-Pentane & $6 \pm 8$ & LOD & 67 & 33 & $2 \pm 2$ & LOD & 9 & 74 \\
\hline n-Pentane & $4 \pm 5$ & LOD & 35 & 17 & $3 \pm 1$ & LOD & 8 & 32 \\
\hline 2-methylPentane & $3 \pm 4$ & LOD & 27 & 82 & $3 \pm 3$ & LOD & 15 & 90 \\
\hline 3-methylPentane & $2 \pm 2$ & LOD & 20 & 85 & $1 \pm 1$ & LOD & 10 & 95 \\
\hline n-Hexane & $2 \pm 2$ & LOD & 25 & 42 & $2 \pm 1$ & LOD & 6 & 56 \\
\hline Benzene & $20 \pm 18$ & LOD & 179 & 5 & $10 \pm 8$ & LOD & 32 & 42 \\
\hline Cyclohexane & $2 \pm 3$ & LOD & 16 & 93 & $1 \pm 1$ & LOD & 2 & 96 \\
\hline i-Octane & $2 \pm 1$ & LOD & 5 & 96 & $3 \pm 3$ & LOD & 8 & 96 \\
\hline n-Heptane & $2 \pm 1$ & LOD & 13 & 54 & $2 \pm 1$ & LOD & 6 & 65 \\
\hline Toluene & $5 \pm 11$ & LOD & 149 & 29 & $2 \pm 1$ & LOD & 8 & 70 \\
\hline n-Octane & $1 \pm 1$ & LOD & 7 & 81 & $2 \pm 1$ & LOD & 5 & 88 \\
\hline Ethylbenzene & $2 \pm 2$ & LOD & 7 & 95 & & & & 100 \\
\hline $\mathrm{m}+\mathrm{p}$-Xylene & $4 \pm 4$ & LOD & 19 & 94 & & & & 100 \\
\hline o-Xylene & $3 \pm 2$ & LOD & 8 & 98 & & & & 100 \\
\hline
\end{tabular}

a $\% \mathrm{BDL}$ indicates the percentage of samples where the compound of interest was below the limit of detection (LOD; see Table 3)

observed in the free and upper troposphere, and, the ranges of mixing ratios are larger than in air masses influenced by stratospheric air. The timescales of mixing and transport of air masses observed by CARIBIC are generally much longer than the chemical lifetimes of many of the NMHC measured. Upper tropospheric air masses that are encountered have usually not been in the boundary layer for a week or more prior to sampling, and in the lowermost stratosphere air masses are considerably much older, as the timescales of tropospherestratosphere exchange are on the order of weeks to months. This results in concentrations of many compounds frequently being below their limit of detection, and is particularly true in the extra-tropics, where about $40 \%$ of the flight time is spent in the transition layer above the tropopause.

Typical NMHC results are exemplified during a series of flights between Frankfurt, Germany and Guangzhou, China and between Guangzhou and Manila in the Philippines during February of 2008 (Fig. 4). The flights began on 25 February, leaving Frankfurt at 21:00 UTC and arriving in Guangzhou at 08:00 UTC on 26 February. A roundtrip flight was conducted between Guangzhou and Manila between 09:00 and 15:00 UTC on 26 February, and the aircraft left Guangzhou at 20:00 UTC, returning to Frankfurt at 04:00 UTC on 27 February. This flight was selected both because it has a number of features that are characteristic of NMHC measured in CARIBIC samples and also because measurements of greenhouse gases from the same flight were discussed in another publication (see Schuck et al., 2009).
The two samples having the highest levels of NMHC were collected at the beginning of the flight from Frankfurt to Guangzhou and have 8-day back-trajectories originating in the boundary layer over the Atlantic Coast of North America; the same air mass origin is also observed for the second to last sample, collected at 02:00 UTC, however elevations in NMHC are not as substantial. Conversely, the lowest values of NMHC represent samples collected in the tropopause layer and/or lowermost stratosphere; these samples are also characterized by increased potential vorticity $\left[\mathrm{PV}>2 \mathrm{PVU}\left(10^{-6} \mathrm{~K} \mathrm{~kg}^{-1} \mathrm{~m}^{2} \mathrm{~s}^{-1}\right)\right]$ and ozone concentrations $\left(\mathrm{O}_{3}>100 \mathrm{ppbv}\right)$, as well as decreased levels of carbon monoxide $(\mathrm{CO}<50 \mathrm{ppbv})$. As stated above, the lifetimes of many of the NMHC measured are shorter than the times scales of troposphere-stratosphere exchange, and significantly lower mixing ratios are observed, as well as many below the detection limit. The remaining samples represent upper tropospheric air and backwards trajectories calculated for these samples indicate no recent influence by boundary layer air.

While NMHC in the upper tropospheric samples are fairly homogeneous, they do exhibit a weak altitudinal dependence, with mixing ratios generally decreasing with increasing altitude (Fig. 5). The return flight from Guangzhou to Frankfurt was at slightly lower altitudes than the flight to Guangzhou from Frankfurt, resulting in mixing ratios that are somewhat higher. This relationship is observed for many individual flights, although the relationship is not consistent 

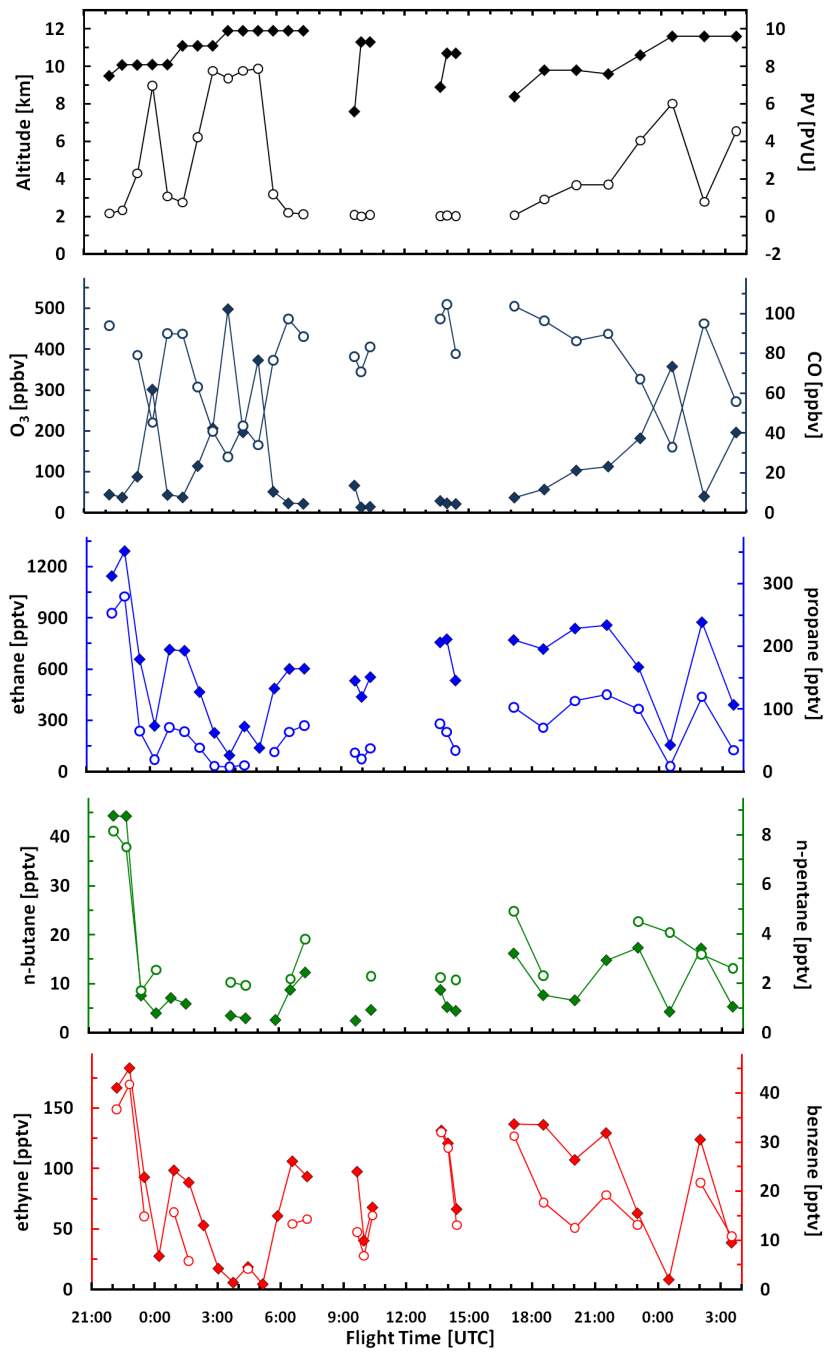

Fig. 4. Mixing ratios for select NMHC during a series of flights between Frankfurt, Guangzhou and Manila during February 2008 (see text for description). Closed diamonds refer to the scale on the left while open circles refer to the scale on the right of each plot. Samples collected through 08:00 UTC are from the flight from Frankfurt and Guangzhou; samples collected between 09:30 and 15:30 UTC are from the round trip flight between Guangzhou and Manila (3 on each leg); samples collected after 17:00 UTC represent the return from Guangzhou to Frankfurt.

between flights and there is no obvious latitudinal trend when considering CARIBIC data as a whole, as NMHC mixing ratios are also dependent on a number of other factors such as season, latitude, and prevailing meteorological conditions.

\section{Summary and conclusions}

Over 900 whole air samples have been collected since 2005 during monthly flights of the CARIBIC system and analyzed for NMHC, allowing for the regular analysis of NMHC in the upper troposphere and lowermost stratosphere. Hydrocarbon

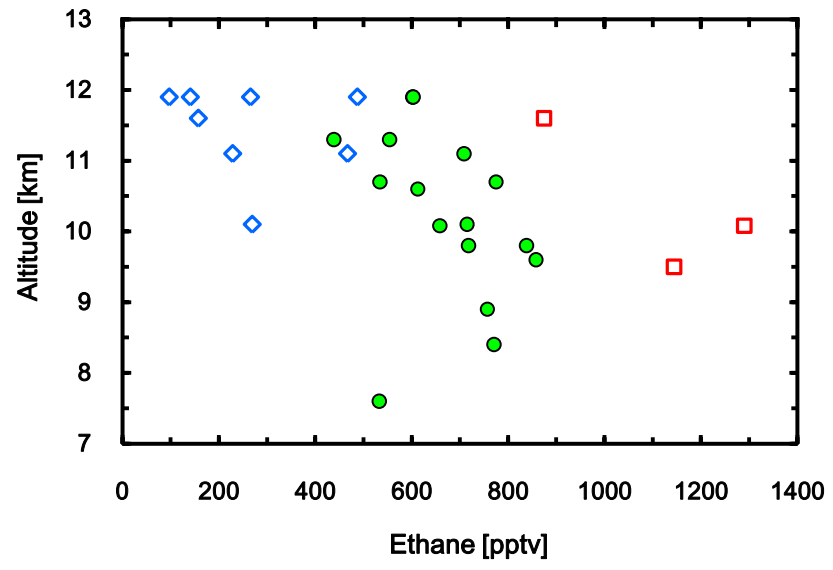

Fig. 5. Relationship between ethane mixing ratios and altitude during return flights between Frankfurt, Guangzhou and Manila in February 2008. Tropospheric samples are represented by filled circles, open squares represent samples with backward trajectories originating in North America and open diamonds represent samples with stratospheric influence.

analysis comprises GC-FID measurements of a suite of 20 individual gases from 28 glass sampling flasks filled during a series of monthly flights. The precision of the system was found to be better than $6 \%$ for all compounds and better than $2 \%$ for most (at $1 \sigma$ ). Inter-comparison between standards from the first phase of CARIBIC and the second phase show that the two are using closely related and easily traceable scales, and inter-comparison of standards with an outside institution indicate accuracies within the system precision as well as compliance with the WMO-GAW VOC guidelines.

Measured NMHC mixing ratios span three orders of magnitude, from a few pptv for shorter lived compounds (e.g. pentanes, toluene) to one or two ppbv for the much longer-lived ethane. Although the limits of detection for the analysis are very low (1-3pptv), there were still a large number of samples where the more reactive species were below the detection limit. This was more frequent in samples that exhibited stratospheric influence than in samples collected in the upper troposphere, and is a product of the longer transport times associated with tropospherestratosphere exchange. Results from a series of flights between Frankfurt and East Asia during February 2008 show the range of NMHC concentrations in the different air masses that might be intercepted during a typical CARIBIC flight. Very low NMHC are observed in the extra-tropical tropopause/lowermost stratosphere, while samples collected in the upper troposphere and free troposphere exhibit much more homogeneous background levels as well as very elevated NMHC in air masses of more recent origin in the boundary layer. The tropospheric samples also show a weak dependence on altitude, although this relationship is not consistent when considering all CARIBIC samples. 
Observed differences between NMHC in tropospheric and stratospheric regimes can be qualitatively attributed to air mass transport and chemical processing, and likely have potential to provide more quantitative information. As the CARIBIC container continues to be deployed monthly, it is hoped that the growing number of NMHC measurements will provide a wider statistical base for these discussions.

Acknowledgements. The authors would like to thank all of the CARIBIC partners at our partner institutions, at Lufthansa Airlines and Lufthansa Technik. Particular thanks are owed to Martin Koerner for his assistance with NMHC analysis, to Claus Koeppel for his work on the TRAC system and Dieter Scharffe for the container operation. We would also like to thank Rainer Steinbrecher and Stephan Thiel of the IMK-FKU for their work on the WMO-GAW VOC audit. The GC system was initially set up by Bohdan Randa and Pavel Matuska. Further information about CARIBIC, as well as information on obtaining CARIBIC data can be found at http://www.caribic-atmospheric.com/.

The service charges for this open access publication have been covered by the Max Planck Society.

Edited by: D. Riemer

\section{References}

Apel, E. C., Calvert, J. G., Gilpin, T. M., Fehsenfeld, F., and Lonneman, F: Nonmethane Hydrocarbon Intercomparison Experiment (NOMHICE): Task 4, ambient air, J. Geophys. Res., 108, 4300, doi:10.1029/2002JD002936, 2003.

Assonov, S., Taylor, P., and Brenninkmeijer, C. A.: A system for high quality $\mathrm{CO}_{2}$ isotope analysis of air samples collected by the CARIBIC Airbus A340-600, Rapid Commun. Mass Sp., 23, 1347-1363, 2009.

Brenninkmeijer, C. A. M., Crutzen, P. J., Fischer, H., Güsten, H., Hans, W., Heinrich, G., Heintzenberg, J., Hermann, M., Immelmann, T., Kersting, D., Maiss, M., Nolle, M., Pitscheider, A., Pohlkamp, H., Scharffe, D., Specht, K., and Wiedensohler, A.: CARIBIC - Civil aircraft for global measurement of trace gases and aerosols in the tropopause region, J. Atmos. Ocean. Tech., 16, 1373-1383, 1999.

Brenninkmeijer, C. A. M., Crutzen, P., Boumard, F., Dauer, T., Dix, B., Ebinghaus, R., Filippi, D., Fischer, H., Franke, H., Frieß, U., Heintzenberg, J., Helleis, F., Hermann, M., Kock, H. H., Koeppel, C., Lelieveld, J., Leuenberger, M., Martinsson, B. G., Miemczyk, S., Moret, H. P., Nguyen, H. N., Nyfeler, P., Oram, D., O'Sullivan, D., Penkett, S., Platt, U., Pupek, M., Ramonet, M., Randa, B., Reichelt, M., Rhee, T. S., Rohwer, J., Rosenfeld, K., Scharffe, D., Schlager, H., Schumann, U., Slemr, F., Sprung, D., Stock, P., Thaler, R., Valentino, F., van Velthoven, P., Waibel, A., Wandel, A., Waschitschek, K., Wiedensohler, A., Xueref-Remy, I., Zahn, A., Zech, U., and Ziereis, H.: Civil Aircraft for the regular investigation of the atmosphere based on an instrumented container: The new CARIBIC system, Atmos. Chem. Phys., 7, 4953-4976, 2007,

http://www.atmos-chem-phys.net/7/4953/2007/.
Colman, J. J., Swanson, A. L., Meinardi, S., Sive, B. C., Blake, D. R., and Rowland, F. S.: Analysis of a wide range of volatile organic compounds in whole air samples collected during PEMtropics A and B, Anal. Chem., 73, 3723-3731, 2001.

Ehhalt, D. H., Rohrer, F., Blake, D. R., Kinnison, D. E., and Konopka, P.: On the use of nonmethane hydrocarbons for the determination of age spectra in the lower stratosphere, J. Geophys. Res., 112, D12208, doi:10.1029/2006JD007686, 2007.

Fraser, P. J., Oram, D. E., Reeves, C. E., Penkett, S. A., and McCulloch, A.: Southern hemispheric halon trends (1978-1998) and global halon emissions, J. Geophys. Res., 104, 15985-16000, 1999.

IGAC: Special Issue on routine measurements from mobile platforms (CARIBIC, MOZAIC, CONTRAIL, TROICA, cargo ships), IGAC Newsletter 37, 2-30, 2007.

Mühle, J., Zahn, A., Brenninkmeijer, C. A. M., Gros, V., and Crutzen, P. J.: Air mass classification during the INDOEX Ronald Brown cruise using measurements of non-methane hydrocarbons, $\mathrm{CH}_{4}, \mathrm{CO}_{2}, \mathrm{CO},{ }^{14} \mathrm{CO}$ and $\delta^{18} \mathrm{O}(\mathrm{CO})$, J. Geophys. Res., 107, 8021, doi:10.1029/ 2001JD000730, 2002.

Grenfell, R., Brookes, C., Vargha, G., Quincey, P., Milton, M., Woods, P., and Harris, P.: EURAMET 886 comparison of multicomponent ambient VOC measurements final report, National Physical Laboratory, London, UK, NPL Report AS29, 2008.

O'Sullivan, D. A.: Temporal and spatial variability of halogenated compounds and other trace gases, Ph.D. thesis, University of East Anglia, UK, 2007.

Parrish, D. D., Stohl, A., Forster, C., Atlas, E. L., Blake, D. R., Goldan, P. D., Kuster, W. C., and de Gouw, J. A.: Effects of mixing on hydrocarbon mixing ratios in the troposphere, J. Geophys. Res., 112, D10S34, doi:10.1029/2006JD007583, 2007.

Plass-Dülmer, C., Schmidbauer, N., Slemr, J., Slemr, F., and D'Souza, H.: European hydrocarbon intercomparison experiment AMOHA part 4: Canister sampling of ambient air, J. Geophys. Res., 111, D04306, doi:10.1029/2005JD006351, 2006.

Pollmann, J., Helmig, D., Hueber, J., Plass-Dülmer, C., and Tans, P.: Sampling, storage, and analysis of $\mathrm{C}_{2}-\mathrm{C}_{7}$ non-methane hydrocarbons from the US National Oceanic and Atmospheric Administration Cooperative Air Sampling Network glass flasks, J. Chromatogr. A, 1188, 75-87 2008.

Rhee, T. S., Brenninkmeijer, C. A. M., Mühle, J., van Velthoven, P. F. J., Hermann, M., Zahn, A., Oram, D. E., Scharffe, D. H., Koeppel, C., Fischer, H., and Lelieveld, J.: A case study of rapid mixing across the extratropical tropopause based on Civil Aircraft for the Regular Investigation of the Atmosphere Based on an Instrumented Container (CARIBIC) observations, J. Geophys Res., 110, D22301, doi:10.1029/2005JD005890, 2005

Rudolph, J., Johnene, F. J., and Khedim, A.: Problems connected with the analysis of halocarbons and hydrocarbons in the nonurban atmosphere, Int. J. Environ. Anal. Chem. 27, 97-122, 1986.

Scheele, M., Siegmund, P., and Velthoven, P. V.: Sensitivity of trajectories to data resolution and its dependence on the starting point: In or outside a tropopause fold, Meteorol. Appl., 3, 267273, doi:10.1002/met.5060030308, 1996. 
Schuck, T. J., Brenninkmeijer, C. A. M., Slemr, F., Xueref-Remy, I., and Zahn, A.: Greenhouse gas analysis of air samples collected onboard the CARIBIC passenger aircraft, Atmos. Meas. Tech., 2, 449-464, 2009,

http://www.atmos-meas-tech.net/2/449/2009/.

Smyth, S., Bradshaw, J., Sandholm, S., Liu, S., McKeen, S., Gregory, G., Anderson, B., Talbot, R., Blake, D., Rowland, S., Browell, E., Fenn, M., Merrill, J., Bachmeier, S., Sachse, G., Collins, J., Thornton, D., Davis, D., and Singh, H.: Comparison of free tropospheric western Pacific air mass classification schemes for the PEM-West A experiment, J. Geophys. Res., 101, 1743-1762, 1996. van Velthoven, P. F. J.: Meteorological analysis of CARIBIC by KNMI, http://www.knmi.nl/samenw/campaign_support/ CARIBIC/\#LH, last access: 10 August 2009, 2009.

World Meteorological Organization - Global Atmospheric Watch Program (WMO-GAW): Global Long-Term measurements of Volatile Organic Compounds (VOCs), World Meteorological Organization, Geneva, Switzerland, WMO-GAW Report Number $171,2007$. 